\title{
Learning and Instruction
}

\section{Outlining the teaching-learning process: Piotr Gal'perin's contribution}

\author{
Jacques Haenen *
}

IVLOS Institute of Education, Utrecht University, PO Box 80127, NL-3508 TC Utrecht, The Netherlands

\begin{abstract}
The Russian psychologist Lev Vygotsky (1896-1934) was one of the most influential psychologists of the 20th century. As a psychologist following in his footsteps, Piotr Gal'perin (1902-1988) could justifiably be called a Vygotskian, but he departed from Vygotsky's sociocultural theory and developed its educational implications. The formative role of education is significant in Vygotsky's notion of a zone of proximal development (ZPD). Gal'perin extended Vygotsky's "zone" to also include a teaching-learning model of the formation of mental actions. This model integrates the notions of mediation, activity and internalization. In doing so, Gal'perin outlines steps in the teaching-learning process, formulates a set of conditions for the development of mental actions and shows the teacher's role. This article summarizes Gal'perin's learning-psychological theory and discusses its use in today's classrooms. (C) 2001 Elsevier Science Ltd. All rights reserved.
\end{abstract}

Keywords: Gal'perin; Learning; Teaching; Vygotsky; Zone of proximal development

\section{Introduction}

Piotr Gal'perin was the last of a generation of Russian psychologists who had personal contact with Lev Vygotsky, the founder of the sociocultural school in Russian psychology. Vygotsky's theory emerged from the context of the first decades of the 20th century and represented a new approach to psychology with tremendous promise. Gal'perin can be considered among those who further developed this approach. He obtained degrees in medicine and psychology, and through this dual

* Fax: +31-30-253-2741.

E-mail address: j.haenen@ivlos.uu.nl (J. Haenen). 
profession became a prominent "Vygotskian" who played an active role in almost all of the major discussions in Russian psychology. His name is especially associated with his attempts to transform the sociocultural approach to human development into a model of the teaching-learning process (Haenen 1996, 2000).

In 1930, Gal'perin was involved in the foundation of the so-called Kharkov School in Russian psychology. At that time, Kharkov, then the capital of the Ukraine, served as a haven for scientists trying to avoid the hectic centre of Soviet affairs. Vygotsky and his co-workers (A.R. Luria, A.N. Leont'ev, L.I. Bozhovich and A.V. Zaporozhets) were also invited to Kharkov and all went, except for Vygotsky himself. The members of the Kharkov School were the first in Soviet psychology to draw attention to the concept of "activity" (Kozulin, 1990). The Kharkovites studied the genesis of a particular mode of psychological functioning in combination with the individual's ongoing practical activity. Gal'perin (1936) contributed to this line of research with his publication on the problem of practical intelligence and the use of tools by animals and children. Köhler's (Köhler, 1925) and Bühler's (Bühler, 1930) classic research in this field was criticized by Vygotsky (1930/1978) because they made a direct analogy between practical intelligence in the child and particular kinds of responses by apes. Vygotsky emphasized the differences and attributed an important role to speech, signs and symbols (semiotic mediational means) as unique human tools in the child's practical activity. Gal'perin followed Vygotsky, but attributed an additional crucial role to human activity. The development of semiotic means has its basis in the specific content of practical, human activity. Gal'perin linked the Kharkovian approach to activity with the Vygotskian terms "mediation" and "internalization". In order to specify their contents, he investigated the process by which children become familiar with simple household tools (spoon, comb, hammer) and described the development of tool-mediated activity.

Though Gal'perin did not use these terms in his pioneering studies, he paid attention to the cognitive processes of orienting and regulating in relation to the different features of the learning task. For example, as early as 1943, he designed a special device for measuring the execution of arm movements and studied the restoration of this motor function following impairment as a result of bullet wounds (Gal'perin, 1943). Based on this research, he designed a rehabilitation program for disabled veterans (Leont'ev \& Zaporozhets, 1960). According to Gal'perin, such a program is most successful if, in addition to isolated exercises, purposeful and meaningful actions are practised. Practical activity together with meaningful learning were the pillar stones of Gal'perin's rehabilitation therapy. In further research, Gal'perin tried to extend this approach to the whole domain of learning and teaching. He perceived learning in terms of a transition (internalization) from action to thought and suggested the steps concerning the teaching-learning process of generating mental activity "from the outside".

\section{The formation of mental actions}

One of the cornerstones of Vygotsky's sociocultural theory is the concept of internalization (Arievitch \& Van der Veer, 1995; Van der Veer \& Valsiner 1991, 
1994; Wertsch, 1985). According to Gal'perin (1967), Vygotsky brought the concept of internalization into mainstream Russian psychology and gave it a special meaning, which it had not previously had in other theories. Vygotsky views psychological functions and the means of mediating them as emerging out of the child's social interaction with adults and peers. Before these functions become an integral part of its personality, they manifest themselves in the "outer" world as interaction between the child and the people around him, or, as Vygotsky (1930/1981) puts it: "it is through others that we develop into ourselves" (p. 161). He formulated this idea in his often cited "general genetic law of cultural development", stating that a psychological function appears twice: first on the social plane, and then on the psychological plane (p. 163). As a consequence, to put it in current terminology, psychological functions are basically "socially distributed". Traditionally, these functions (attention, memory, cognition) have been treated as being properties of the individual mind. This concept of "individuality" laid the basis of much educational practice. Nowadays - and Vygotsky has been instrumental in it-this concept has been totally changed. In recent educational psychology, it has been advocated that psychological functions are encapsulated and distributed in a community of learners. This turning away from a predominantly individualized to a contextualized and social approach to education has entered the mainstream of educational psychology (cf. Forman, Minick, \& Stone, 1993; Karpov \& Haywood, 1998; Kozulin, 1998; Mercer, 1995; Rogoff, 1998; Salomon \& Perkins, 1998; Wells, 1999). Gal'perin added to this in exploring a new educational program within a Vygotskian framework.

In order to elaborate the social dimension of psychological functioning, Vygotsky developed his well-known notion of a "zone of proximal development" (ZPD). He placed the interaction with adults and more competent peers at the very heart of this zone, providing "the foundation upon which, in an ideal world, the education of children would be organized" (Cole, 1996, p. 111). Therefore, the formative role of education is significant in Vygotsky's ZPD. But unfortunately (according to Gal'perin), Vygotsky did not expand on it in the light of its educational implications, but continued to use cross-sectional and cross-cultural comparative methods to diagnose mental development. Gal'perin tried to fill this gap and outlined some steps in the teaching-learning processes that take place in "Vygotsky's zone". For this purpose, Gal'perin developed his model of the formation of mental actions.

In the early 1950s, Gal'perin with some co-workers (among them V.V. Davydov and N.F. Talyzina) began to study the mental actions and concepts (elementary arithmetical and geometrical concepts) that have to be learned in the classroom. They studied the qualitative changes that the teaching-learning process has to undergo to provide mature and fully fledged mental actions. On the basis of empirical and theoretical knowledge, Gal'perin first made an analysis of the properties (or parameters) of an action.

\section{The parameters of an action}

Whatever the content of the teaching-learning process, there is always some kind of action involved, and these actions vary widely. A descriptive model is necessary 
in order to specify the properties of the actions and ways of developing them during the acquisition of knowledge and skills. Within the framework of activity theory, actions are conceived as conscious attempts to change objects according to some intended goal (Gal'perin, 1992b). The concept of action has to be very broadly conceived. It refers to the sawing of a branch, the decoration of a room, the doing of a sum, the using of a concept, etc. The examples show that an action can be executed simultaneously on several levels of abstraction. Moreover, on all these levels an action may have different qualities. So, Gal'perin classifies each concrete form of an action by two distinctive and relatively independent properties or parameters: the level of abstraction and the quality of an action.

The first parameter is the level of abstraction. An action may be performed on four basic levels: the materialized, the perceptual, the verbal, and the mental level. At the materialized level, the action is performed with the aid of physical objects or their material representations-models, pictures, diagrams, displays. At the perceptual level, the action is based on information stored in images and performed without manipulation of the physical objects or their representations (e.g. refurbishing a room by looking around and "moving" the furniture mentally). At the verbal level, the action is performed by "speaking aloud"; at this level the external objects are no longer needed. At the mental level, the action is exclusively performed internally ("in the head") and both external objects and audible speech are unnecessary.

The second parameter concerns the quality of an action. According to Gal'perin, this quality is determined by three indicators: generalization, abbreviation and mastery. Generalization represents the degree to which those properties of the object of an action that are constant and essential to its performance, are isolated and distinguished from the non-essential and variable ones. Generalization occurs when, from the very beginning, several varieties of the material involved are used in order to carry out the learning tasks. This prevents the learner from attending to nonessential properties of the objects. Abbreviation indicates whether all operations which are originally part of an action, are in fact executed. As an action develops, the number of operations is reduced and the action becomes abbreviated. Initially, an action will be executed in its most extended form. Then, some of its operations will be joined together or "telescoped". Mastery includes such features of actions as the ease and the rate with which they are carried out. For example, an action has not been mastered sufficiently when a child can carry out an action only under the teacher's guidance.

Neither parameter (level of abstraction and quality of an action) should be considered in isolation. The levels of abstraction and the indicators of the quality of an action stand in different relation to each other and are not independent. Gal'perin conceptualized these parameters in such a way that they could be integrated into an instrument which provides information about the relevant aspects of an action. They allow us to analyze the structure of an action with respect to its objects and intended goal. In addition, they give us the necessary information about how to outline the teaching-learning process and the teachers' and learners' involvement in it. 


\section{Steps in the formation of actions}

Gal'perin brought the two parameters together in a teaching strategy. This strategy can be conceptualized as a process of internalization, in which Gal'perin distinguishes four steps for an action to pass through before becoming a fully fledged mental action. Depending on the action to be learnt, the specific learning task and the learners' prior knowledge, the steps may be abbreviated, combined together or even skipped. Also the sequence of the steps can be changed. So, Gal'perin's stepwise approach is a working model or blueprint for outlining the teaching-learning process and the instructional interventions for the teacher to support and guide the learners.

Around 1950, when starting with his first experiments, Gal'perin wanted to study the psychological rationale for the execution of learning tasks and the coming into being of the accompanying mental actions. Initially, he called the new teaching strategy the "stepwise procedure". However, he later regretted (personal communication) the fact that his approach had become known by this limiting heading, because it no longer reflected its main content. Nevertheless, under this heading it became wellknown as a pillar of the reorganization of reading and arithmetics by the experimental school led by D.B. El'konin (El'konin, 1973; see also Amano, 1999) and V.V. Davydov (Davydov \& Andronov, 1981; Davydov, 1995). Gradually, Gal'perin abandoned the idea of a strict sequence of steps in the teaching-learning process and started to emphasize the distinctive elements that form the basis of the process. He suggested that every teacher has some kind of sequencing in mind and uses it as a preparation device during lesson planning. An experienced teacher always uses such a sequence as a blueprint with steps that can be changed at short notice depending on what happens in the classroom. This is not as easy as it sounds, because there is no one way of using such a blueprint. It asks for skilled teacher activity and it should be deliberately practised. Gal'perin's blueprint for the teaching-learning process contains the following steps.

\subsection{Orientation}

First, for a new action to be learnt, it is brought to the learner's attention and delineated within his or her horizon of problems to be solved. The learner receives an "advance organizer" of the action and its goal. This motivates the learner for the ensuing teaching-learning process. Although motivation is a long-term affair, this first step is meant to provide the initial requirements in order to stimulate motivation and to maintain it during further learning. According to Gal'perin, this requires that the learning contents be presented as a meaningful whole from the beginning of the teaching-learning process (as will be illustrated later using an example of handwriting instruction). This increases the student's personal involvement in the learning process that follows. Presenting knowledge as a meaningful whole implies presenting it as some kind of “tomorrow's knowledge". First, students have to understand and accept the affective, motivational and cognitive value of the to-be-acquired knowledge before the actual appropriation and ability to use it is at stake. This can be considered as one of the practical consequences of Vygotsky's concept of “develop- 
mental teaching" and its maxim that education "is only useful when it moves ahead of development" (Vygotsky, 1987, p. 212). According to Vygotsky, education should lead development in order to call to life those functions that "are in a state of maturation lying in the zone of proximal development" (p. 212). Gal'perin ensures the student's initiation into the learning task and her first steps in Vygotsky's "zone" by starting the teaching-learning process with an extensive phase of orientation.

According to Gal'perin, every human action is accomplished on the basis of some orientation, which largely determines its quality. In Gal'perin's teaching strategy, orientation plays a key role and is designed to provide the learner with all the information necessary for the correct execution of a new action. Gal'perin (1989c, 1992ad) introduced the term "orienting basis of an action" (OBA) to refer to the whole set of orienting elements by which the learner is guided along in the execution of an action. In addition, Gal'perin introduced a second term, "Scheme of a Complete Orienting Basis of an Action" (SCOBA) which signifies the complete set of conditions which are to be taken into account. Thus, an OBA is the actual learner's orienting basis, while a SCOBA is the desired and intended form of the orienting basis leading to the correct execution of an action. An OBA does not ensure correct execution, whereas a SCOBA does. An OBA is something learners have at their disposal, whereas a SCOBA is an externally presented scheme or "cognitive map", which has to be adopted. Being externally presented to the learner, a SCOBA remains constant, while an OBA gradually changes during the course of the teaching-learning process.

What are the contents of a SCOBA? Generally speaking, it contains as much information as possible on the execution of an action. According to Gal'perin (1989c), a SCOBA includes the intended output, means and objects of the action, put in summarized form on an orienting chart. This chart (an "operational thinking scheme" or "cheat sheet") gives the course of the action and the sequence of its operations in such a way that it serves as a "tool of action". The orienting chart is a "cheat sheet" in the literal sense, providing a clear picture of the components of a SCOBA in such a way that the learners can adopt them. It appears that under these circumstances the content of the charts is learnt unexpectedly easily (as is often the case when learners are making cheat sheets) and incidentally in the process of executing learning tasks. Empirically, this advantage of the use of orienting charts has been verified by Carpay (1974) who designed a chart for choosing the correct form of Russian verbs; Mettes, Pilot, \& Roossink (1981) who designed a chart that students can use to orient themselves to problem solving in a thermodynamics course; and Van Engen (1994b) who used it as the basis for teaching the motor skill of handwriting in elementary school (as discussed below).

Working with orienting charts implies that the action is initially executed on the materialized level. After the explanation and its understanding during the initial orientation, the learner becomes familiar with the new action. This can be achieved by means of the manipulation of physical objects or their representations; such as the touching, replacing, and putting together of objects by a child during an arithmetical task. However, when the object transcends the limits of direct perception, it is much more convenient to execute the action using visual representations as substi- 
tutes for physical objects. These representations are part of an orienting chart and may take the form of models, displays, diagrams, maps or drawings, depicting the properties and relationships of the objects essential to the action.

At first glance, it might seem that the materialized forms of an action are necessary only in the early years of the educational system or at the initial stages of a course or curriculum. However, according to Talyzina (1981), closer study shows that even for adults the learning of fundamentally new knowledge first requires at least partial materialization by means of all kinds of orienting charts.

\subsection{Communicated thinking}

When an action has been sufficiently learnt using physical objects or their representations, it is necessary to separate the action from its previous materialized support and to lift the action to overt or social speech ("communicated thinking"). The learners are taught to communicate about the action and to think aloud as they perform it without any direct dependence on the tangible objects or their materialized representations. What was previously a materialized or practical action now becomes a verbal one. Speech becomes the sole carrier of both the action and its objects. Gal'perin (1969) emphasizes that an action in overt speech is no longer materialized, nor is it yet a mental action. The learner is not yet able to perform the action through "inner" speech, i.e. "in the head". Overt speech is a transitional phase between the materialized and the mental action. Gal'perin (1989b) gives two arguments for emphasizing the necessity of overt speech. First, the action of overt speech is a "theoretical" one. The action has become free from the necessity of manipulating tangible things or their representations; these are replaced by words and reflected in speech. This means that the action becomes generalized. The second argument refers to the function of speech as a means of communication. The effect of overt speech is determined by its social role. Learners must execute the action verbally so it is comprehensible not only to themselves but to others as well. The execution of the action meets the requirements of communication and, in particular, the requirements of communicating in the language of the given discipline, from which the curriculum subject has been drawn. Due to its distinctive communicative feature, overt speech could be called "communicated thinking". The latter term links Gal'perin's line of reasoning with Vygotsky's general genetic law stating that social speech becomes the source of thought. It is only after the socially-based attitude of the learner toward the new action has been adopted that proper learning of the action occurs. In sum, it is both the generalizing and communicative functions of speech that make overt speech effective. Its favourable effects point to the importance of verbal interaction, small-group work and cooperative learning in the classroom. Working together, thinking-aloud and elaborating explanations may be positively related to students' achievements (Cohen, 1994).

\subsection{Dialogical thinking}

The benefits of communicated thinking may be improved if it is additionally combined with methods that provoke all kinds of dialogical thinking. In teacher education 
courses better results are reached if, in addition to group discussions, the student teachers make use of a logbook for reflection, looking back on classroom experiences and formulating intentions (Korthagen, 1999). Similarly, student teachers' computermediated exchanges (distribution lists, Internet bulletin boards) could be compared with the way Gal'perin conceptualizes dialogical thinking. In his teaching strategy, after speaking aloud about the action, the learner is encouraged to speak covertly. This transition from overt speech into "speech minus sound" requires a transformation of the structure of speech itself. "In the mind" the overt form of speech takes the shape of a "deep structure" (cf. Chomsky), or, as Gal'perin (1969) called it, "the audible image of the word". According to Gal'perin, such an "audible image" can only evolve after the action has passed through overt speech. The psychological significance of an audible image lies in the fact that it is more stable and stronger than a perceptual image, which should evolve on the basis of merely a materialized action without the subsequent overt speech. Though the action has gone "inward", speech is still the carrier of both the action and its objects. Because of this, Gal'perin (1989b) called it "external speech to oneself" (p. 53), because the execution of the action still meets the requirements of communication. The execution relies on an "inner dialogue" and reflects the "increasing dialogicality that characterizes intramental processes" (Wertsch, 1991, p. 90). Owing to this process of dialogicality, covert speech could be called "dialogical thinking". During this type of thinking, the action becomes more and more routine and abbreviated. When the action has been developed almost to the point of being automatic, there can be a transition to acting purely mentally.

\subsection{Acting mentally}

During the soundless utterance of the action, learners begin to execute all the operations of the mental action quickly and without error. They can give the answer as soon as they receive the proper information with which to solve the learning task. The teacher abandons control of the outcomes of the successive operations and moves on to control of the final outcome of the action. Now the action has been abbreviated and telescoped. The action has been transformed into a mental phenomenon and has become a chain of images and concepts. The learner "just knows that's how it is" (Gal'perin, 1957, p. 221). So, as a result of subsequent levels of abstraction (materialized-verbal-mental) the action has attained a new form: it has become "pure" thought. This form, as Gal'perin (1989b) argued, represents a qualitatively new level of psychological functioning: the mental action has an orienting function. The action is mentally executed with the aid of mental images and concepts, in which real life situations are represented. On the basis of the representation of the "problem space", a person can foresee the effects of his own or somebody else's actions, change the actions to fit the distinctive features of the situation and anticipate options on the basis of previous experiences. As a result of this process, mental actions obtain the proper orienting function, which, after all, is what it is all about. Putting it somewhat differently, Gal'perin sees the ability of looking ahead (orientation) as a precondition to and even a prime aspect of learning. In current 
educational psychology, this ability is considered part of the student's self-regulation, because looking ahead leads to cognitive planning and monitoring. Pintrich \& De Groot (1990) have empirically found that such components of self-regulation foster academic performance. This could explain the positive effects Gal'perin observed in his experimental approach to handwriting instruction.

\section{An example: the motor skill of handwriting}

Gal'perin's approach to teaching-learning processes is illustrated here with the aid of a method to teach the motor skill of handwriting in elementary schools. Gal'perin $(1982,1989)$ provided the theoretical basis for the Dutch curriculum project on "Handwriting in the elementary school" (Van Engen, 1994a,b), currently used by about one-third of Dutch elementary schools (about 2000 schools).

In the early 1950s, Gal'perin and his co-workers took as their starting point a psychological analysis of the formation of the motor skill of handwriting (Pantina, 1957). At that time, it was common practice in Soviet elementary schools to teach handwriting using an exercise book having three lines with slanted $\left(65^{\circ}\right)$ lines across (see Fig. 1). The teacher required the children to correctly place each segment of the grapheme in the corresponding section of the grid. Under these conditions it is necessary that the children have a precise visual image of the grapheme. However, the most basic factors in the development of the writing skill are both the presence of the correct motor image and a rapid shift from visual to motor control strategies of the writing movements. To achieve such a shift, Gal'perin decided to develop a teaching method based on the dissection of the grapheme into segments. What, however, could serve as the basis of such a dissection?

According to Gal'perin (1982), the method that was developed was based on Vygotsky's ideas about units of analysis in psychological research. Vygotsky (1987) defined a unit as "a product of analysis that possesses all the basic characteristics of the whole" (italics in the original, p. 46). In writing graphemes, the learning task consists of the correct reproduction of its shape. In Gal'perin's view, in this case the unit of the shape can be found in a "segment of continuous movement". Where the line begins or changes its direction, indices are added so that each discrete segment is located between two such indices. In Fig. 2, taken from the Dutch teachers' manual, the indices of the grapheme $m$ are indicated. This figure illustrates what Gal'perin has called an "orienting chart" showing the learner how to use a generalized procedure while modeling a grapheme. Each segment of a grapheme differs

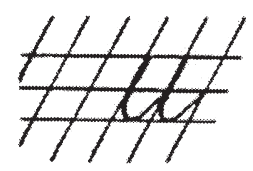

Fig. 1. Example of the grid from an exercise book used for teaching handwriting in Russian elementary schools (Pantina, 1957, p. 121). 


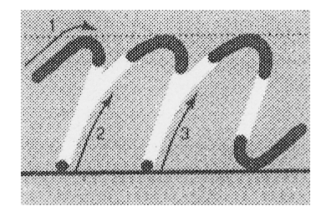

Fig. 2. Example of the model used to introduce the principle of analysing a grapheme in Dutch elementary handwriting instruction (Van Engen, 1994b, p. 70).

from every other in length and position within the slanted lines. A grapheme may begin and end on these lines or between them, and may run close to or separate from them. Consequently, indices are necessary as a reference, otherwise no exact reproduction of a grapheme can be made. Gal'perin distinguished two types of indices: (1) dividing indices (often points) for marking the beginnings and endings of a segment, and (2) guiding indices for maintaining the movement of very long segments. These indices bear a resemblance to the numbered arrows proposed by Berninger et al. (1997), who designed a method for improving handwriting. Both Gal'perin and Berninger et al. provide support for orientation during the writing of graphemes.

Gal'perin taught the children to establish independently (though under the teacher's guidance) the inventory of indices through analyzing the shapes of graphemes. He designed a teaching strategy that has become his trademark. This strategy is determined by its emphasis on a proper orienting basis and the execution of materialized and verbal actions favourable to the internalization of the motor control of the writing movements. Briefly, it proceeds as follows (as described in more detail in Haenen, 1996). The teacher offers a model of a grapheme, explains the purpose of the indices, and shows how one can isolate them. The explanation is accompanied by a demonstration of only the first grapheme. Instead of providing the inventory of indices, the teacher explains the principle of identifying them, namely, they are placed where the line begins, ends and changes its direction. Beginning with the second grapheme, the pupils independently (though under the teacher's guidance) isolate all indices, while the teacher merely corrects the mistakes. Thus, the pupils establish for themselves the content of the orienting basis. This basis is complete and general, i.e. the orienting basis contains a general principle, which is applicable to any specific grapheme.

To assess the results of his method, Gal'perin designed a test series. After the pupils had been taught, they were asked to correctly copy unfamiliar and unknown graphemes from the Cyrillic, Georgian and Roman alphabets. The pupils analyzed and copied the given graphemes quite easily. It appeared that transfer was not only complete in the specific domain of writing Russian graphemes, but extended to other alphabets and to graphic representations in general, in which the position of objects on a plane is relevant, such as blueprints, drawings, and trajectories of moving bodies. Gal'perin and his co-workers were surprised at how easily the pupils copied graphic displays. Apparently, Gal'perin's approach had enabled the pupils to transfer the method of analyzing graphemes far beyond its boundaries. Because of the success 
of this "near-far transfer" (Brainerd, 1975), it is not surprising that other researchers have been giving special attention to Gal'perin's handwriting instructions.

\section{Conclusion}

In this final section, Gal'perin's work is related to two aspects of educational psychology focused on in current educational literature: orientation and language use. First, the gist of Gal'perin's concept of orientation may be found in the way students learn to orient themselves to the distinctive features of the learning task. In current educational parlance, orientation integrates aspects of self-regulated learning (especially metacognitive strategies) as related to classroom academic performance. Gal'perin conceptualized these components in his concept of a SCOBA (including an "orienting chart") as the core of an orienting basis. This is illustrated in his model of handwriting instruction. As the results indicated, the handwriting-SCOBA facilitates students' self-regulated learning, described by De Corte (1996, p. 38) as the capacity and willingness to skillfully monitor and evaluate their own learning process. This asks for active and independent students for which teachers should provide powerful learning environments in which self-regulated learning can be most successfully acquired (cf. Boekaerts, 1999). When teachers do this properly, we have "instruction". When this is guided by "systematic and validated principles and theories, instruction becomes a design science" (Salomon \& Perkins, 1998, p. 20). Gal'perin's approach facilitates the teaching-learning process, one of its aims being to develop students' self-regulatory skills. To underpin these skills, Gal'perin points to the importance of the very early steps in the teaching-learning process. These early steps are organized by him around an orienting basis aiming at presenting the subject matter as a meaningful whole. This was illustrated by Gal'perin's general principle for analyzing graphemes as a starting point for handwriting instruction.

Secondly, special attention should be given to Gal'perin's interpretation of language use in the classroom. Gal'perin emphasizes that the elaboration of an action during communicated and dialogical thinking is of the utmost importance for the formation of fully fledged mental actions. He makes explicit how dialogue and communication in classrooms support individual learning. His line of reasoning fits contemporary sociocultural approaches to interaction and instructional discourse (Mercer, 1995; Rogoff, 1998; Wells, 1999). Gal'perin sees communicated thinking as a highly structured and distinctive way of acting verbally, comprehensible not only to the learners themselves but to others as well. The execution of the action meets the requirements of communicating in the language of the given subject matter. The teacher represents the discipline from which the subject matter has been drawn and functions as an expert. Gal'perin's approach to the teacher's role bears resemblance to the way teachers take on their role in reciprocal teaching (Palinscar, Brown, \& Campione, 1993). The teacher is a dialogue leader, introducing students to a similar role through explicit instruction of metacognitive strategies for learning from written texts. The students learn how to pose questions to fellow students, who are trying to effectively comprehend texts. Not surprisingly reciprocal teaching ech- 
oes lines of reasoning developed in the tradition of sociocultural psychology (cf. Wertsch, 1998).

Although orientation and language use are powerful tools in the hands of the teacher, they should not be considered in isolation. The strength of Gal'perin's approach lies in the way he conceptualized the complexity and wholeness of teaching-learning processes by means of a theoretical framework. The different aspects of the approach must be properly integrated to bring about fully fledged mental actions as the basic components of a cognitive "tool kit (...) that permits one to get to higher grounds mentally" (Bruner, 1986, p. 73).

\section{References}

Amano, K. (1999). Improvement of schoolchildren's reading and writing ability through the formation of linguistic awareness. In Y. Engeström, R. Miettinen, \& R.-L. Punamäki, Perspectives on activity theory. Cambridge: Cambridge University Press.

Arievitch, I., \& Van der Veer, R. (1995). Furthering the internalization debate: Gal'perin's contribution. Human Development, 38, 113-126.

Berninger, V. W., Vaugham, K. B., Abbott, R. D., Abbott, S. P., Rogan, L. W., Brooks, A., Reed, E., \& Graham, S. (1997). Treatment of handwriting problems in beginning writers: Transfer from handwriting to composition. Journal of Educational Psychology, 89, 652-666.

M. Boekaerts (1999). Self-regulated learning [special issue]. International Journal of Educational Research, 31 (6).

Brainerd, C. J. (1975). Structures-of-the-whole and elementary education. American Educational Research Journal, 12, 369-378.

Bruner, J. (1986). Actual minds, possible worlds. Cambridge, MA: Harvard University Press.

Bühler, K. (1930). The mental development of the child. New York: Harcourt, Brace.

Carpay, J. A. M. (1974). Foreign-language teaching and meaningful learning. A Soviet Russian point of view. ITL Review of Applied linguistics, 25-26, 161-187.

Cohen, E. G. (1994). Restructuring the classroom: Conditions for productive small groups. Review of Educational Research, 64, 1-35.

Cole, M. (1996). Cultural psychology. A once and future discipline. Cambridge, MA: Harvard University Press.

Davydov, V. V. (1995). The influence of L.S. Vygotsky on eduation theory, research, and practice. Educational Researcher, 24 (3), 12-21.

Davydov, V.V., \& Andronov, V.P. (1981). The psychological conditions for the origination of ideal actions. Project Paper No. 81-2. Madison: Wisconsin Research and Development Center for Individualized Schooling.

De Corte, E. (1996). Instructional psychology: overview. In E. De Corte, \& F. E. Weinert, International encyclopedia of developmental and instructional psychology (pp. 33-43). Oxford: Pergamon.

El'konin, D. B. (1973). USSR. In J. Downing, Comparative reading (pp. 551-579). London: MacMillan.

Forman, E. A., Minick, N., \& Stone, C. A. (1993). Contexts for learning. Sociocultural dynamics in children's development. Oxford: Oxford University Press.

Gal'perin, P.Ia. (1936). Psikhologicheskoe razlichie orudy cheloveka i vspomogatel'nych sredstv u zhivotnych i ego znachenie [Psychological differentiation of human beings' tool and the auxiliary means of animals and their significance]. Unpublished master's thesis, University of Khar'kov, Ukraine.

Gal'perin, P.Ia. (1943). Psychological factors in medical gymnastics. In Works of the Ukrainian Psychoneurological Institute. Kiev, pp. 321-329. (In Russian.)

Gal'perin, P. Ia. (1957). An experimental study in the formation of mental actions. In B. Simon, Psychology in the Soviet Union (pp. 213-225). London: Routledge and Kegan Paul.

Gal'perin, P. Ia. (1967). On the notion of internalization. Soviet Psychology, 5 (3), 28-33. 
Gal'perin, P. Ia. (1969). Stages in the development of mental acts. In M. Cole, \& I. Maltzman, A handbook of contemporary Soviet psychology (pp. 249-273). New York: Basic Books.

Gal'perin, P. Ia. (1982). Intellectual capabilities among older preschool children: on the problem of training and development. In W. W. Hartup, (pp. 526-546). Review of child develoment research, 6. Chicago, IL: University of Chicago Press.

Gal'perin, P. Ia. (1989a). Study of the intellectual development of the child. Soviet Psychology, 27 (2), 26-44.

Gal'perin, P. Ia. (1989b). Mental actions as a basis for the formation of thoughts and images. Soviet Psychology, 27 (2), 45-64.

Gal'perin, P. Ia. (1989c). Organization of mental activity and the effectiveness of learning. Soviet Psychology, 27 (2), 65-82.

Gal'perin, P. I. (1992a). Human instincts. Journal of Russian and East European Psychology, 30 (4), 22-36.

Gal'perin, P. Ia. (1992b). The problem of activity in Soviet psychology. Journal of Russian and East European Psychology, 30 (4), 37-59.

Gal'perin, P. Ia. (1992c). Stage-by-stage formation as a method of psychological investigation. Journal of Russian and East European Psychology, 30 (4), 60-80.

Gal'perin, P. Ia. (1992d). Linguistic consciousness and some questions of the relationship between language and thought. Journal of Russian and East European Psychology, 30 (4), 81-92.

Haenen, J. (1996). Piotr Gal'perin: psychologist in Vygotsky's footsteps. Commack, NY: Nova Science Publishers.

Haenen, J. (2000). Gal'perian instruction in the ZPD. Human Development, 43 (2), 93-98.

Karpov, Y. V., \& Haywood, H. C. (1998). Two ways to elaborate Vygotsky's concept of mediation. Implications for instruction. American Psychologist, 53 (1), 27-36.

Köhler, W. (1925). The mentality of apes. London: Routledge and Kegan Paul.

Korthagen, F. A. J. (1999). Linking reflection and technical competence: the logbook as an instrument in teacher education. European Journal of Teacher Eduction, 22 (2/3), 191-207.

Kozulin, A. (1990). Vygotsky's psychology. A biography of ideas. London: Harvester Wheatsheaf.

Kozulin, A. (1998). Psychological tools. A sociocultural approach to education. Cambridge, MA: Harvard University Press.

Leont'ev, A. N., \& Zaporozhets, A. V. (1960). Rehabilitation of hand functions. Oxford: Pergamon Press.

Mercer, N. (1995). The guided construction of knowledge: Talk amongst teachers and learners. Clevedon: Multilingual Matters.

Mettes, C. T. C. W., Pilot, A., \& Roossink, H. J. (1981). Linking factual and procedural knowledge in solving science problems. Instructional Science, 10, 333-361.

Palinscar, A. S., Brown, A. L., \& Campione, J. C. (1993). First-grade dialogues for knowledge acquisition and use. In E. A. Forman, N. Minick, \& C. A. Stone, Contexts for learning. Sociocultural dynamics in children's development (pp. 43-57). Oxford: Oxford University Press.

Pantina, N. S. (1957). The formation of the motor habit of writing depending on the type of orientation to the task. Voprosy Psikhologii, 3 (4), 117-132.

Pintrich, P. R., \& De Groot, E. V. (1990). Motivational and self-regulated learning components of classroom academic performance. Journal of Educational Psychology, 82, 33-40.

Rogoff, B. (1998). Cognition as a collaborative process. In D. Kuhn, \& R. S. Siegler, Handbook of child development, 5th ed., Vol. 2. (pp. 679-744). New York: John Wiley and Sons.

Salomon, G., \& Perkins, D. N. (1998). Individual and social aspects of learning. In P. D. Pearson, \& A. Iran-Nejad, (pp. 1-24). Review of research in education, 23. Washington, DC: AERA.

Talyzina, N. F. (1981). The psychology of learning. Theories of learning and programmed instruction. Moscow: Progress.

Van der Veer, R., \& Valsiner, J. (1991). Understanding Vygotsky: A quest for synthesis. Oxford: Blackwell.

Van der Veer, R., \& Valsiner, J. (1994). The Vygotsky reader. Oxford: Blackwell.

Van Engen, A. (1994a). Schrijven in de basisschool [Handwriting in the elementary school]. Groningen: Jacob Dijkstra. 
Van Engen, A. (1994b). Schrijven als oefenvak. Handboek voor didactiek en praktijk [Exercising handwriting. Handbook of the didactics of writing graphemes]. Vries: Schrijfpedagogisch Instituut.

Vygotsky, L.S. (1930/1978). Tool and symbol in child development. In M. Cole, V. John-Steiner, S. Scribner, \& E. Souberman, Mind in society. The development of higher psychological processes (pp. 19-30). Cambridge, MA: Harvard University Press.

Vygotsky, 1930/1981Vygotsky, L.S. (1930/1981). The genesis of higher mental functions. In J.V. Wertsch, The concept of activity in Soviet psychology (pp. 144-188). Armonk, NY: M.E. Sharpe.

Vygotsky, L. S. (1987). The problem and method of investigation. Collected works. Problems of general psychology, Vol. 1. New York: Plenum Press.

Wells, G. (1999). Dialogic inquiry: Towards a sociocultural practice and theory of education. Cambridge: Cambridge University Press.

Wertsch, J. V. (1985). Vygotsky and the social formation of mind. Cambridge, MA: Harvard University Press.

Wertsch, J. V. (1991). Voices of the mind. A sociocultural approach to mediated action. London: Harvester Wheatsheaf.

Wertsch, J. V. (1998). Mind as action. Oxford: Oxford University Press. 